\title{
La cuestión de la crítica en la teoría marxista
}

\author{
The question of criticism in Marxist theory
}

Fernando Forero Pineda ${ }^{1}$

\author{
Resumen
}

Este artículo se escribe bajo el supuesto de que existe un sentimiento generalizado entre los científicos sociales, según el cual la teoría social contemporánea ha menester de una revisión radical de las obras de aquellos escritores que establecieron el marco de referencia fundamental de la moderna teoría social. En este orden de ideas, tres nombres sobresalen por encima de los demás: Karl Marx, Émile Durkheim y Max Weber. Mi propósito en este trabajo es hacer un estudio en torno al concepto de crítica de Marx relacionándolo con los conceptos de praxis, crítica de la economía política, crítica de las ideologías y la crítica como acción política. Tales conceptos son analizados en relación con la perspectiva teórica del marxismo occidental y, especialmente, en relación con la idea que Habermas se hace de la teoría de Marx.

\section{Palabras clave:}

Marx, marxismo occidental, filosofía de la praxis, crítica.

\section{Abstract}

This article is written in the belief that a widespread view exists among social scientists that contemporary social theory needs a radical revision of the works of those writers who established the principal frames of reference of modern theory of society. In this respect, three names stand out above all others: Karl Marx, Émile Durkheim and Max Weber. The objective of this work is to examine and analyze Marx's concept of critique regarding the concepts of praxis, critique of the political economy, critique of ideology, and critique as political action in relation to the theoretical perspective of western Marxism and, especially, in relation to Habermas's idea of Marx's theory.

\section{Keywords:}

Marx, western marxism, philosophy of praxis, critique.

Artículo recibido el 14 de febrero de 2011 y aprobado el 19 de agosto de 2011

1 Licenciado en Ciencias Sociales, Universidad Pedagógica Nacional. Estudiante de la Maestría en Filosofía, Universidad Nacional de Colombia. Correo electrónico: ferdinando102000@yahoo.com 
El objetivo de las reflexiones aquí reunidas es desarrollar la idea de la teoría marxista como una teoría crítica y, en la medida en que el espacio lo permita, delimitar su estatus frente a concepciones del concepto de crítica de teorías de otro linaje. Es un artículo que se trata de cerciorar de la estructura del marxismo como una teoría proyectada explícitamente con intención política, y para el que la lectura de Habermas sobre la obra de Marx sirve como hilo conductor. El texto empieza haciendo una presentación de los fundamentos del concepto de praxis y en este punto inevitablemente conecta con la tradición filosófica a la que Marx se remite (I); en seguida desarrolla un análisis de la relación existente entre el concepto de crítica y el concepto de alienación, así como entre la crítica y la crítica de la economía política y de las ideologías (II). La exposición del marxismo como una teoría concebida con un interés práctico constituye el apartado final del texto (III).

\section{El concepto de praxis como plataforma}

Hegel desarrolla en la Lógica el concepto de trabajo bajo el título de la teleología. La teleología se conceptúa como el resultado de la realización de fines subjetivos. Lo que a Hegel le interesa es mostrar cómo el proceso teleológico subjetivo ha de ser realizado a través de los medios por él movilizados, es decir, cómo para la realización de un fin el sujeto ha menester de medios. El famoso pasaje afirma:

Que el fin se refiera inmediatamente a un objeto $y$ que él mismo haga de medio, así como que determine a través de éste a otro, puede ser considerado como poder, en la medida en que el fin aparece como de naturaleza completamente diferente a la del objeto y los dos objetos son del mismo modo totalidades autónomas entre sí. Pero que el fin se ponga en la relación mediata con el objeto y que entre sí y el mismo objeto intercale otro objeto, puede ser interpretado como la astucia de la razón. La finitud de la racionalidad posee, por este lado, el hecho de que el fin se relacione con la presuposición, es decir, con la externalidad del objeto. De este modo, pone delante un objeto como medio, hace trabajar externamente al mismo en lugar del suyo, abandona la extenuación y se mantiene tras él fren- te al poder mecánico... En esta medida el medio es algo más elevado que los fines finitos de la utilidad externa; el arado es más honroso de lo que son los placeres que son preparados gracias a él y que son fines. La herramienta se mantiene, mientras que los placeres inmediatos perecen y serán olvidados. El hombre posee en sus herramientas el poder sobre la naturaleza externa, si bien según sus fines está mucho más sometido a ella (Hegel, 1982, p. 175).

Según esto, el proceso de trabajo encuentra su punto central en el hecho de que en la actividad productiva el trabajador $-y$, junto con él, la razón- se objetiva a sí mismo en los medios de producción. Es así como la dialéctica de la objetivación, desarrollada primeramente en la Fenomenología del espíritu al modo de una negatividad, alteridad o externalidad del concepto, ${ }^{2}$ encuentra su lugar en la Lógica; con ello, así lo celebra y conmemora Marx, Hegel conceptúa la esencia del trabajo al tiempo que aprehende al hombre objetual -o a la objetualización del hombre en los medios productivos- como el resultado de su propio trabajo (Habermas, 1987, p. 211). Tanto como Hegel, Marx reconoce una racionalidad que mora en el interior del proceso de trabajo, pues, por una parte, el hombre $-y$ la razón- se objetualiza en las herramientas de trabajo, y porque, por otra, merced a tales herramientas la especie humana entra en un proceso de mediación con la naturaleza. Mas la objetivación tiene para Marx el doble sentido de autoexteriorización en los medios productivos y autoexteriorización en los productos para el consumo; lo cual quiere decir que tan importantes como las herramientas de trabajo son para él los "placeres" que se preparan gracias a ellas "y que son fines".

En este punto Marx se deja guiar por la actividad productiva del artista y, en concreto, por el concepto que Schiller se hace del arte. Así como

2 Esta es, como habremos de recordar, una de las más famosas críticas de la filosofía especulativa de Hegel a la filosofía de Shelling. Este, considera Hegel, no estudia la negatividad o alteridad del automovimiento del concepto. "Lo ilimitado... [aparece en él]... todavía abstracto, y es mejor lo ilimitado, lo que se determina a sí mismo, lo que a sí mismo se limita" (Hegel, 2006, p. 69). 
el artista pone fuera de sí sus fuerzas esenciales en sus obras sirviéndose para ello de herramientas (pincel, lienzo, pinturas), de la misma forma también el trabajador manifiesta lo más íntimo de sí en el producto de su trabajo usando para ello medios de producción (Habermas, 1989, p. 84). Además, Schiller y Marx hacen un diagnóstico de su época y de la modernidad, en el que los conceptos de arte y trabajo prácticamente se solapan. Ambos entienden la modernidad como un contexto en el que, merced a la aparición de ese sujeto cartesiano y kantiano que según Max Weber cristaliza en orientaciones de la personalidad, estructuras institucionales y formas culturales (Habermas, 2008a, p. 195ss; Habermas, 2008b, p. 427ss.), los lazos comunitarios estallaron en mil pedazos y en el que ya no cabe echar mano de la religión para rehabilitar lo que otrora era una vida colectiva. Es en este punto donde se hacen más patentes las hipotecas del concepto de trabajo de Marx respecto del concepto de arte de Schiller, pues mientras éste le salió al paso a los problemas de su época sirviéndose del arte como medio para desarrollar la fuerza reconciliadora, aquel lo hizo mediante el concepto de trabajo (Habermas, 1989, p. 62ss.).

Marx, al transferir esa productividad estética a la "vida laboral del hombre como especie", puede entender el trabajo como autorreflexión colectiva de los productores. Sólo la asimilación del trabajo industrial a un modelo cargado de contenido normativo le permite establecer una diferencia entre la objetivación de las fuerzas esenciales del hombre y su extrañamiento, entre una praxis que puede satisfacerse retornando a sí misma y una praxis cuyo automovimiento queda interrumpido y fragmentado. (Habermas, 1989, p. 85).

Según Marx, el hombre se duplica prácticamente en la actividad productiva -tanto en medios productivos como en productos para el consumo-, y a la vez se contempla a sí mismo en el mundo resultante y creado por él: el trabajo hace que el mundo objetivo aparezca como la realidad empírica y la obra del hombre (Habermas, 1987, p. 207).
De aquí se deriva la primera forma del concepto de praxis, a saber, la praxis como praxis conclusa. 3 Así como en Schiller el artista realizado es aquel que, en actitud contemplativa, se apropia de su obra, así también en Marx el trabajador realizado es aquel para quien el producto de su trabajo retorna a sí. Lo mismo ocurre con los medios productivos; en tanto medios de producción social, sólo satisfacen una praxis conclusa cuando están al servicio de la sociedad en su conjunto. El trabajo se entiende como un proceso circular de extrañamiento, objetualización y reapropiación de las fuerzas del propio ser (Berger y Luckmann, 1984, p. 33), y por ello el proceso de mediación del hombre con la naturaleza recoge en síla autorrealización de los sujetos activos que intervienen en él. En los Manuscritos de París el joven Marx desarrolla una especie de "imagen del hombre". Se trata de la esencia objetualizada del hombre, el cual, en cuanto que ser natural, se produce a sí mismo ante todo trabajando. Enajenación de las fuerzas esenciales e intercambio con la naturaleza, apropiación de las objetualizadas y exteriorizadas fuerzas esenciales, realización del hombre y reproducción racional de la vida social, constituirían el contexto antropológico fundamental de la filosofía de la praxis (Habermas, 1987, p. 221).

Empero, en el trabajo alienado -en las sociedades de clases- queda interrumpida esta praxis conclusa, es decir, se altera el ciclo de autoexteriorización y reapropiación de las fuerzas esenciales objetivadas. El joven Marx analiza, sobre todo en los Manuscritos de París y en los Escritos de juventud, las estructuras del trabajo alienado y se sirve para ello de algunas categorías centrales, traducidas al lenguaje de Feuerbach, de la Fenomenología del espíritu de Hegel. En el trabajo alienado el productor ve cortado el acceso al goce de unos productos en los que tenía que reencontrarse a sí mismo, porque una clase se apropia de tales productos (Habermas, 1989, p. 85); por lo mismo, los medios de producción quedan al servicio de una determinada clase social y no a disposición de la sociedad en su conjunto. Marx hubiera querido

3 Huelga recordar que quien acuñó la expresión Filosofía de la praxis fue Jean-Paul Sartre (D. Lindenberg, 1987, 330). 
analizar este contexto como una estructura constante de la historia humana. Ciertamente, fue eso lo que intentó hacer en (v., gr.) La ideología alemana; pero de hecho en toda su obra desarrolló un análisis específico de una situación concreta, a saber, la situación de la clase trabajadora puesta de manifiesto por la dialéctica de trabajo asalariado y capital. He aquí la otra forma del concepto de praxis: la praxis como praxis inconclusa o como praxis interrumpida.

Marx denomina a la historia de la alienación prehistoria de la humanidad; pues sólo una sociedad en la que la praxis quede nuevamente conclusa, ha de ser digna de consideración dentro del decurso histórico. Pero lo que él nombra como prehistoria de la humanidad tiene también el sentido de una crítica del concepto de trabajo de Hegel. Hegel transforma las categorías alcanzadas mediante la teleología del trabajo en determinaciones del proceso vital social, y con ello universaliza el hecho de que "los medios" sean más importantes que "los fines". Marx se vuelve polémicamente contra tal idea. El problema del trabajo alienado -piensa él- radica también en que el trabajo muerto predomina sobre el vivo, la mediación rige sobre lo a mediar, los medios productivos son más importantes que los fines llevados a cabo, es decir, «el arado... [sigue siendo]... más honroso que los placeres preparados gracias a él y que son fines». Dentro de las estructuras del trabajo alienado el hombre vive para trabajar; mientras que dentro de las estructuras de la praxis conclusa el hombre trabaja para vivir (Habermas, 1996; Habermas, 1987, p. 212). La sociedad del trabajo no es para Marx en modo alguno la sociedad de la austeridad y de la necesidad, como tampoco es la sociedad de la ausencia de trabajo. Por todo esto Marx acusa a Hegel de sólo haber visto el lado positivo del trabajo, pero no su aspecto negativo. 4

4 Para un análisis más detallado de las críticas de Marx a Hegel (Vásquez, 2000).

\section{Determinación preliminar del concepto de crítica: trabajo alienado, crítica de la economía política y crítica de las ideologías}

Con el análisis del trabajo alienado, el plexo vital social de las sociedades de clases queda interpretado $y$ cuestionado como un contexto integral de coerción. Como hemos dicho, Marx de hecho desarrolló tal análisis sobre una situación concreta, a saber, la situación de la clase obrera dentro del marco de la sociedad burguesa. En el capitalismo los medios productivos toman la forma de propiedad privada, mientras que la auto objetivación del obrero en el producto de su trabajo se ve subsumida por el proceso de apropiación privada de la producción social. En esta medida, la propiedad privada es considerada como la cápsula en la que permanecen cautivas las fuerzas esenciales sustraídas al hombre, como el punto oscuro en el que se concentra el oscurecimiento del mundo o como el nudo en el que están atados todos los hilos de la corrupción del mundo (Habermas, 1987, p. 252). La alienación llega a un punto tal que la fuerza de trabajo del obrero no sólo se convierte en un objeto y en una existencia externa, sino también en algo que existe de manera independiente y ajena al trabajador y alcanza un poder autónomo frente a él (Habermas, 1987, p. 211). La crítica aparece aquí al modo de un desvelamiento del contexto social burgués como trama integral de trabajo alienado.

Por otra parte, la teoría marxista es una de las primeras en tomar la palabra en términos económicos, y es por ello que investiga el sistema capitalista bajo el aspecto de una crítica de la economía política; en esta investigación el concepto de crítica salta a primera vista. En el primer volumen de El capital, Marx analizó el "fetichismo de la mercancía". Según él, sólo cabe generalizar la forma mercancía a todos los productos del trabajo cuando el mismo trabajo toma la forma mercancía, y esto es, además, una condición para que el modo de producción se haga capitalista (Marx, 1972). Con la imagen del trabajador asalariado libre que asiste al mercado para vender como única mercancía su fuerza de trabajo, queda satisfecha la condición histórica bajo la cual el proceso de trabajo se independiza respecto del 
hombre y la producción de valores de uso palidece enteramente frente a la producción de valores de cambio. Pero lo que a Marx le interesa, sobre todo en el primer volumen de El capital, es saber cómo es que es posible el proceso de valorización del capital. Si la acumulación de riqueza ha de llevarse a cabo bajo las condiciones del intercambio de equivalentes, entonces el poseedor de dinero tiene que comprar mercancías a su valor y venderlas a su valor. No obstante, al final del proceso deberá extraer más valor del que introdujo. Tiene que haber, por tanto, una mercancía específica que, como todas las restantes, se compre por su valor, pero cuyo valor de uso esté constituido de manera tal que a partir de su consumo se origine valor. Esa mercancía es el trabajo. De ahí que, por oposición a Adam Smith y David Ricardo, para quienes la acumulación de capital se origina en el mercado, Marx piense que tiene sus orígenes en el valor, esto es, en el plusvalor generado por el trabajo. Marx, por tanto, saca la acumulación de riqueza del ámbito del mercado para investigarla en el proceso de producción (Marx, 1984, cap. VII y ss; Habermas, 1987, p. 239). El valor de la fuerza de trabajo se mide en relación con el valor de la reproducción de la vida del obrero, así como en relación con el trabajo socialmente necesario que la producción de mercancías requiere para que el obrero genere los medios necesarios para su subsistencia. Mas el capitalista emplea la fuerza de trabajo adquirida más tiempo del tiempo de trabajo que sería necesario para que reprodujera su propio valor. Este plustrabajo es considerado como plusvalía, y es, a la vez, la fuente de la acumulación de riqueza. Es así como el trabajo asalariado queda identificado como el origen de la plusvalía. Habermas resume la acumulación de capital según la teoría marxista como sigue:

La relación de trabajo asalariado trueca el acto concreto de trabajo en un rendimiento abstracto, esto es, en una aportación funcional al proceso de autorrealización del capital que, por así decirlo, se incauta del trabajo muerto, del trabajo sustraído a los productores. El trueque asimétrico de fuerza de trabajo por salario es el mecanismo que ha de explicar por qué la esfera de las fuerzas esencia- les alienadas y extrañadas de los trabajadores se autonomiza sistemáticamente. Con este supuesto de teoría del valor el contenido estético-expresivo del concepto de praxis queda ampliado con un elemento moral. Pues ahora el trabajo alienado no sólo se desvía del modelo, articulado en términos de estética de la producción, de una praxis que queda conclusa y satisfecha al retornar sobre sí misma, sino también del modelo iusnaturalista del trueque de equivalentes (Habermas, 1989, p. 85).

Marx afirma que las crisis del sistema capitalista tienen su origen necesariamente en el proceso de valorización del capital, es decir, en aquella relación que queda puesta con la apropiación de la plusvalía. Merced a que el proceso de valorización del capital discurre -por así decirlo- autárquicamente, la sociedad no puede detener las consecuencias que desencadena tal proceso. Crisis-producción-sobreproducción-abarrotamiento del mercado-estancamiento-crisis, serían los elementos constitutivos de las crisis del capitalismo (Marx, 1984, cap. XV y ss.). Las crisis desvalorizan el capital existente para, en virtud de ello, poner de nuevo en marcha aceleradamente el proceso de valorización del capital en su totalidad, el cual ha de recaer con posteridad en nuevos stocks. «La crítica de la economía política es también teoría de la crisis en sentido genuino» (Habermas, 1987, p. 237). De este modo, el concepto de crítica enlaza con el de crisis: la crítica es análisis del mundo social como contexto de crisis -y ello quiere decir que la crítica y la crisis proceden de la misma raíz-.

Por lo demás, para Marx las dificultades con que tropezaba una adecuada concepción de la crítica provenían no de las ciencias positivas, sino de las falsas concepciones de la filosofía de su tiempo. Los filósofos se sumergían en meditaciones abstractas, mientras que la ciencia de la naturaleza era un ejemplo paradigmático que a menudo demostraba su verdad. Según esto, un concepto adecuado de crítica requería que justificara su carácter científico frente a la filosofía (McCarthy, 1987, p.p. 35-36). De ahí que la crítica de la economía política, se deje inspirar -o se pretenda inspirada- por los medios de la ciencia: «de ahí que el proceso de realización del 
capital pueda presentarse como una magia que, una vez quede rota, podrá disolverse liberando un sustrato objetivo, que resultará entonces accesible a la administración racional» (Habermas, 1996, p. 268).

En gran medida, el lugar que el trabajo ocupa para Marx está relacionado con la concepción que él tiene del mismo como trabajo social: la actividad productiva del hombre tiene lugar en espacios ideológicamente mediados, es decir, las fuerzas productivas median en la relación del hombre con la naturaleza dentro de determinados vínculos de producción. Empero, la actividad productiva y el mundo social no son considerados por Marx como esferas autónomas entre sí. La última quedó siempre reducida e integrada en la primera. Según él, la reproducción de la humanidad tiene lugar primeramente en el ámbito de la producción de las condiciones materiales de vida. Esta línea -reduccionista- de pensamiento se expuso ampliamente en el prefacio a la Contribución a la crítica de la economía política:

En la producción social de su existencia, los hombres entran inevitablemente en determinadas relaciones que son independientes de su voluntad, relaciones de producción ajustadas a un estadio dado en el desarrollo de las fuerzas materiales de producción. La totalidad de estas relaciones de producción constituye la estructura económica de la sociedad, el fundamento real sobre el que se levanta una estructura jurídica y política y al que corresponden determinadas formas de conciencia social. El modo de producción de la vida material condiciona el proceso general de la vida social, política e intelectual (Marx, 1970, p. 12).

La conciencia social, incluidas las estructuras jurídica y política, adopta formas diseñadas para mantener a los trabajadores dentro de la alienación y para evitar que broten los potenciales de racionalidad de los medios productivos. Mediante la economía política -que es ciencia propiamente dicha en el sentido arriba mencionado y que no es cualquier ciencia sino la única que para Marx mantiene una relación con la sociedad global y que estudia el problema de «cómo repercute la dinámica del sistema económico en los órdenes que integran normativamente la sociedad» (Habermas, 2006a, p. 19)- el analista no sólo entiende el fundamento auténtico de la sociedad burguesa, así como las consecuencias a las que éste inequívocamente conduce; 5 también comprende las configuraciones que toma la conciencia social y ve cómo tales configuraciones aspiran a preservar la sociedad existente. La teoría de Marx es esencialmente una teoría crítica en el sentido de que analiza genuinamente las configuraciones de la conciencia como "crítica de las ideologías", así como la dinámica de la economía capitalista sujeta a crisis cíclicas (McCarthy, 1987, p.p. 36-37); esto significa que la crítica de la economía política tiene también el sentido de una crítica de las ideologías.

\section{La Crítica como actividad político- revolucionaria}

El problema de los jóvenes hegelianos, argumentaba Marx, radica en que su crítica permanece abstracta, capaz a lo sumo de alcanzar «una emancipación simplemente teórica». La emancipación real de los hombre requeriría «la negación de la filosofía hecha hasta el momento, de la filosofía como filosofía» (Marx, 1970b). El concepto de crítica de la teoría marxista reniega de las pretensiones contemplativas de algunas teorías y ve que también la filosofía que ha existido hasta el momento se arroga, a pesar de sus propias pretensiones, un carácter meramente contemplativo (Habermas, 1987, p. 14)6. La teoría marxista es práctica en el doble sentido de que, por una parte, ilustra a sus destinatarios sobre la situación que ocupan dentro de un sistema social antagónico y sobre la constelación de intereses que pueden tornarse conscientes desde su punto de vista,

5 Era precisamente a una aparente independencia de las "leyes" de la vida social respecto de la conciencia de los hombres, a lo que con frecuencia Marx apelaba para justificar el carácter científico de su crítica. Cfr. El Prefacio a la segunda edición de la Crítica de la economía política.

6 Sobre todo para este apartado, cfr. La introducción de Habermas a la segunda edición de Teoría y praxis, algunas dificultades en el intento de mediar teoría y praxis, 1971. 
demostrándoles que, sin saberlo, hacen la historia, que la aparente preponderancia de las relaciones sociales es obra de sus propias manos y que están en condición de transformarlas (Habermas, 1987, p. 47); y de que, por otra parte, conceptúa el contexto en el que la propia teoría puede ejercer una influencia que orienta la acción. De hecho, Marx no queda satisfecho con que el proletariado comprenda su situación, ni tampoco con que se ilustre sobre sí mismo y sobre su papel potencialmente emancipatorio en el decurso histórico; quiere además que su teoría quede engarzada en tal proceso histórico $\mathrm{y}$, por tanto, que aparezca como un momento «necesario, catalizador del mismo contexto vital social» (Habermas, 1987, p. 13). Marx tenía la esperanza de que la filosofía se convirtiera en fuerza material tan pronto como prendiera en las cabezas de las masas. Pues una teoría que pretendiera ser revolucionaria ha de dirigirse a sus destinatarios, para que éstos transformen los conceptos en consignas. La inversión de un mundo corrompido por la alienación no tiene que ser preparada por la contemplación, sino por la praxis política; y la redención de la especie humana debe ser anticipada precisamente por la filosofía de la praxis. Sin embargo, para Marx, el análisis del antagonismo de clases, la introducción, mediación y conducción de la praxis revolucionaria por la teoría, la superación práctica de la alienación y la liberación del potencial emancipatorio de las fuerzas productivas, constituían cuatro momentos conceptualmente trabados entre sí (Lôwy, 1987, p. 332; Habermas, 1987, 409).

Así pues, la teoría no sólo esclarece los orígenes históricos de la dominación, sino que proyecta también el horizonte por donde puede ser superada. Marx persigue, por tanto, «la guerra civil más o menos oculta que se está desarrollando dentro de la sociedad existente», hasta un punto en el que «rompa en revolución abierta» (Marx, 1978, p. 22). Esta es la tercera y última forma que adopta el concepto de praxis: la praxis como actividad crítico revolucionaria, es decir, «la acción política autoconsciente con que los trabajadores asociados rompen el hechizo a que el trabajo muerto tiene sometido al vivo y se reapropian esas fuerzas esenciales que habían sido objeto de una alienación fetichista» (Habermas, 1989, p.p. 85-86). A la praxis revolucionaria queda reservado el papel de romper el autonomizado proceso de autorrealización del capital, liberando al reino de la libertad de los dictados de la necesidad. La revolución, al suprimir la propiedad privada de los medios de producción, suprime también el fundamento que mantiene en marcha a la economía capitalista (Habermas, 1989, p. 415).

Por lo demás, fue a esta epistemología materialista, que en los escritos del joven Marx aparece formulada como teoría de la sociedad, a la que en los años treinta del siglo pasado Max Horkheimer se atuvo para fundamentar el programa de una teoría crítica de la sociedad. Al justificarse a sí misma sólo en el plano metodológico, la ciencia tradicional se desvincula tanto de la conciencia de sus propias raíces sociales como del conocimiento de sus objetivos prácticos. En la negación del contexto práctico de las teorías científicas, Horkheimer y Marcuse no sólo veían el error del positivismo contemporáneo, sino también una deficiencia de la comprensión de la teoría moderna en general: Horkheimer remonta hasta Descartes las raíces de esa autocomprensión positivista que permite que la ciencia aparezca como una empresa pura y enteramente desprendida de los intereses prácticos (Honneth, 1998, p. 449 y ss.). El nombre que Horkheimer da a esta tradición cientificista es el de "teoría tradicional"; a ésta, él y Marcuse oponían la "teoría crítica", entendida como teoría autoconsciente, lo mismo del contexto social del que surge, que de su contexto de aplicación práctica. De ahí que la interpretación dialéctica asuma en Teoría crítica la tarea de conceptuar al sujeto cognoscente a partir de los contextos de la praxis social, a partir de su posición tanto en el proceso del trabajo social como en el proceso de ilustración de las fuerzas políticas sobre sus propias metas. Según Horkeimer, aquí yace la diferencia entre "teoría tradicional" y "teoría crítica": 
Mientras que el especialista, "en cuanto" científico, ve la realidad social junto con sus productos como exterior, y, "en cuanto" ciudadano percibe su interés por ella a través de artículos políticos, de la afiliación a partidos o a organizaciones de beneficencia y de su participación en las elecciones, sin unir ambas cosas $-\mathrm{y}$ algunas otras formas de comportamiento- en su persona de otro modo

\section{Bibliografía}

Berger, P. y Luckmann, T. (1984). La construcción social de la realidad. Buenos Aires: Amarrortu.

Habermas, J. (1987). Teoría y Praxis. Madrid: Tecnos. (1989). El discurso filosófico de la modernidad. Buenos Aires: Taurus.

(1996). La necesidad de una revisión de la izquierda. Madrid: Tecnos.

(2006a). Teoría de la acción comunicativa. Vol. I. México: Taurus.

(2006b). Teoría de la acción comunicativa. Vol. II. México: Taurus.

Hegel, G. W. F. (1982). Ciencia de la lógica. Buenos Aires: Solar.

(2006). Fenomenología del espíritu. Valencia: Pre-textos.

Honneth, A. (1998). Teoría crítica. En A. Giddens y J. Turner (comps), La teoría social, Hoy. Madrid: Alianza.

Horkheimer, M. (1974). Teoría crítica. Buenos Aires: Amarrortu.

Lindenberg, D. (1987). Prolétariat. En P. Ory (comp), Nouvelle histoire des idées politiques. France: Hachette, Collection Pluriel. que, a lo sumo, mediante una interpretación psicológica, hoy, en cambio, el pensamiento crítico está motivado por el intento de suprimir y superar realmente esa tensión, de suprimir la oposición entre conciencia de fines, la espontaneidad y la racionalidad esbozadas en el individuo y las relaciones del proceso de trabajo, fundamentales para la sociedad (Horkheimer, 1974, p. 242).
Lôwy, M. (1987). Marxisme de Marx, marxisme d'Engels. En P. Ory (comp). Nouvelle histoire des idées politiques. France: Hachette, Collection Pluriel.

Marx, K. (1970). Contribución a la crítica de la economía política. Madrid: Alberto Corazón Editor.

(1970b). Introducción a la crítica de la filosofía del derecho de Hegel. En K. Marx y A. Ruge, Los anales franco-alemanes. Barcelona: Ediciones Martínez Roca.

(1972). La génesis del capital. Moscú: Progreso.

(1978). La Guerra Civil en Francia. Pekín, China: Ediciones Lenguas Extranjeras.

(1984). El capital. Barcelona: Orbis.

McCarthy, T. (1987). La teoría crítica de Jürgen Habermas. Madrid: Tecnos.

Vásquez, E. (2000). Prefacio. En G. W. F. Hegel, Filosofía del derecho. Madrid: Biblioteca Nueva. 